\title{
DURATION OF SPLINTING AFTER REPAIR OF EXTENSOR TENDONS IN THE HAND
}

\author{
A Clinical Study* \\ David Stuart, Lusaka, Zambia \\ Formerly at the Robert Jones and Agnes Hunt Orthopaedic Hospital, Oswestry, England
}

After studying the effect of function on the strength of tendon repairs in dogs, Mason and Allen (1941) concluded that immobilisation was necessary for two or three weeks. This had been taught by Mayer (1938) and was followed by Koch (1943) and Bunnell (1948). Since then Miller (1942), Farquharson (1950), Rank and Wakefield (1953), Nemethi (1956), Kelly (1959), Flatt (1959), and Clarkson and Pelly (1962) have all advised a similar time for splintage after tendon repairs. On the other hand, Couch (1939), Romanis and Mitchiner (1948), Handfield-Jones (1949), Iselin (1955), Pulvertaft (1956) and Thatcher (1957) considered early mobilisation to be better. It has not always been made clear by these authors whether or not the recommended periods of immobilisation concerned extensor tendons specifically.

This study was undertaken to show the results with different times of splintage after primary repair of extensor tendons over the metacarpo-phalangeal joints in the hand. The work was undertaken at the Ernest Oppenheimer Hospital which serves the gold mines in Welkom, Orange Free State, South Africa. During the year 1958, 906 Bantu patients with hand injuries were admitted. Of these, 179 had extensor tendon injuries in the region of the metacarpo-phalangeal joints of the fingers (that is, excluding the thumb). Since then, an estimated 200 such patients have been admitted annually.

Standardisation of the after-care has advantages of its own when such large numbers of patients are treated, besides any findings an investigation into the type of after-care might reveal.

When this study was started, the period of splinting varied with each surgeon. Some employed no splintage, yet the results seemed to be satisfactory.

\section{CLINICAL MATERIAL}

All patients had similar injuries; while using a shovel the exposed knuckles struck a sharp picce of quartz rock, which caused an incised wound usually half an inch long (Fig. 1). and cut the extensor tendon over the metacarpo-phalangeal joint.

Patients with more than one finger injured were excluded from the series and those in whom either the index or little fingers had been affected were included only if both the extensor tendons had been severed. Those in whom the tendon was not sutured, or was already infected, and those with joint damage, fractures or extensive skin damage were also excluded. All patients analysed attended a personal follow-up clinic for assessment and if the records were incomplete the case was excluded. Records were kept of a total of 274 patients, but of these only 137 met the requirements given above and were available for analysis.

The tendon was repaired by primary end-to-end suture. Size 000 interrupted silk sutures were inserted under local anaesthesia with 2 per cent procaine hydrochloride with adrenaline. After the repair of the tendon and skin, the hand was dressed with dry gauze and immobilised, from the proximal interphalangeal joints of all fingers to the elbow, on an anterior plaster slab which kept the fingers in full extension at the metacarpo-phalangeal

* Read at the British Orthopaedic Association meeting in London, September 1963. 
joints and the wrist in the position of function (Figs. 2 and 3). All patients were admitted to hospital.

Each patient kept his hand in a sling in elevation but was encouraged to move the proximal and terminal interphalangeal joints freely. No dressings were changed until the sutures were removed on the tenth day unless signs of infection developed, or the bandages became wet or very soiled. The slightest infection -even around the sutures-was noted, and the case recorded as septic.

In the first part of the series, in which a comparison was made between splintage for one and ten days, alternate new patients had the plaster slabs removed next day but the dressings were left undisturbed. Patients freed from plaster were allowed to move their fingers actively and as much as pain would allow.

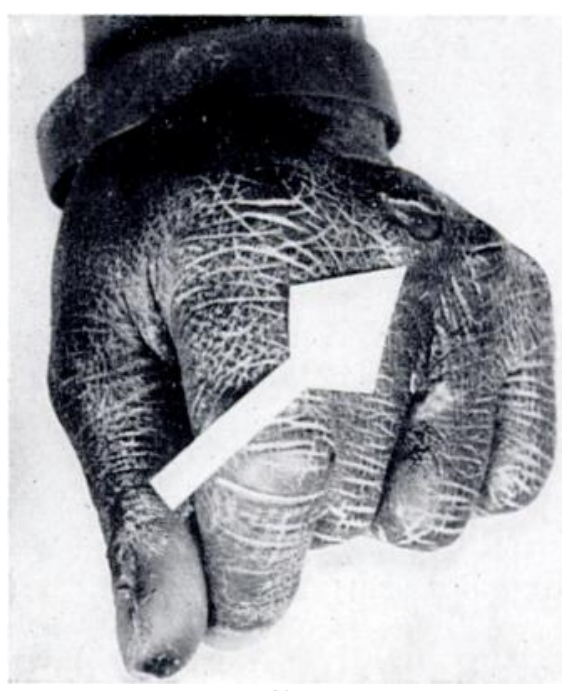

FiG. 1

Typical injury severing the extensor tendon of the middle finger.

In the latter part of the series, devoted to a study of fingers immobilised for three weeks, the plaster slab was altered on the tenth day, when the sutures were removed, the metacarpophalangeal joints being held in slight flexion until the splint was removed at the end of the third week

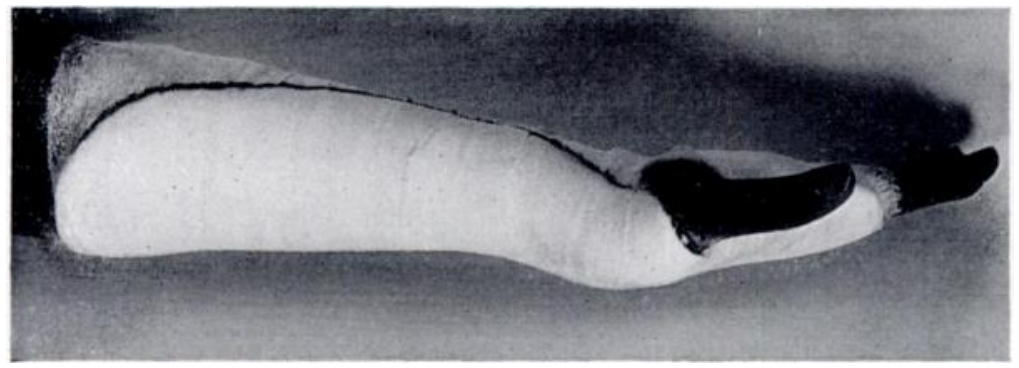

FIG. 2

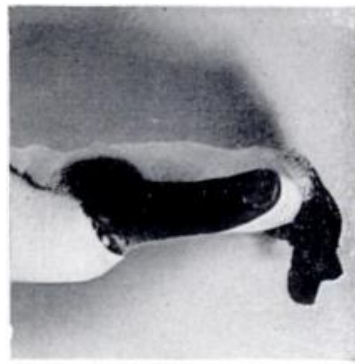

Fig. 3

Figure 2-The type of immobilisation employed for all patients. Figure 3-Showing the movement of the distal two joints of the fingers.

Thus three groups were formed: thirty-five patients splinted for one day, eighty patients splinted for ten days, and twenty-two patients splinted for three weeks. making a total of 137 patients analysed.

Thirty-one patients out of the 137 had physiotherapy in the form of active finger exercises

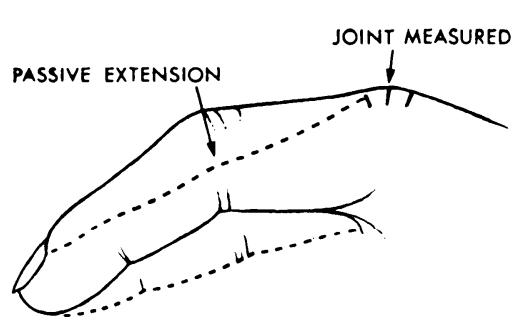

FIG. 4

Diagram to show the method of assessment when extension is lost at the proximal interphalangeal joint. and wax baths once the wound was healed. Physiotherapy was used in patients with some stiffness, and in those who were later found to have a considerable lag to extension and who could not return to work.

An exact record of when the patient returned to work was available, and until they were fit for the original work all were kept in hospital. None returned to convalescent or lighter work unless, because of other circumstances, the lighter work was to be permanent. Thus, there was close supervision of the patient from the time of injury until he returned to work.

VOL. 47 B, NO. 1. FEBRUARY 1965 


\section{ASSESSMENT}

After one month at work each patient was reviewed. If by then he had an excellent result, his records were completed and he was discharged. The remaining patients were then seen regularly, final assessment being made after eight weeks' work.

The assessment was made with a goniometer (Pulvertaft 1956) to measure the angle at the metacarpo-phalangeal joint and to compare this with that on the uninjured hand. The results were assessed according to Miller (1942), as follows. Excellent-full extension and full flexion; good-10 degrees or less of extension lost and full flexion; fair-between 10 and 30 degrees of extension lost, with or without slight loss of flexion; poor-more than 30 degrees of extension lost, with or without severe loss of flexion.

Eleven patients had loss of extension at the proximal interphalangeal joint; in these it was found that the loss of extension was less at the metacarpo-phalangeal joint if the proximal interphalangeal joint was passively extended. Measurement was then carried out only at the metacarpo-phalangeal joint in order to standardise all findings at this joint (Fig. 4).

\section{RESULTS}

General results comparing the different periods of splintage-Good or excellent results were found in 79 per cent if the fingers were splinted for ten days, in 73 per cent splinted for three weeks, and in 60 per cent splinted for one day. Poor results were found in 29 per cent if splinted for one day, in 27 per cent splinted for three weeks, and in only 11 per cent splinted for ten days (Tables I to III).

Sepsis-There was a sepsis rate of 17 per cent (twenty-four patients) which included the least infection. The incidence in the three groups varied (Tables IV to VI) and was least in those splinted for one day and about the same in the other two groups.

Two of the five septic cases splinted for one day had poor results (Table IV) because of joint stiffness. Two of the four septic cases splinted for three weeks had poor results (Table VI) also because of joint stiffness. Of all the twenty-four septic cases seven had poor results of which six had joint stiffness. Only three of the fifteen septic cases splinted for ten days had poor results (Table V); two had joint stiffness and the other had an extension lag.

Time off work-The average time off work in those splinted for one day was 12.3 days, with a range from eight to twenty-eight days; and for ten days 16.3 days, ranging from ten to thirty-five days; and for three weeks 27.3 days, ranging from twenty-one to forty-nine days (Table VII). Among those immobilised for ten days there were six patients who stayed off work for longer than usual; four were infected, one had a haematoma and one had physiotherapy for stiffness. These patients all stayed in hospital for more than three weeks and, although five of the six had excellent results and the other a good result, the average time off work was adversely affected in the group.

Physiotherapy-This was given to nine patients immobilised for one day ( 26 per cent), to sixteen immobilised for ten days ( 20 per cent) and to six immobilised for three weeks ( 27 per cent) (Table VIII).

The poor results in detail-Eight out of the ten patients with poor results who had been splinted for one day had an extension lag. In two others loss of flexion and joint stiffness respectively were caused by infection (Table IX).

Five out of nine patients with poor results who had been splinted for ten days had an extension lag. The other four had loss of flexion (Table X).

All six patients with poor results who had been splinted for three weeks developed joint stiffness with loss of some extension and flexion (Table XI).

The incidence of joint stiffness or loss of flexion increased with the increase in the length of immobilisation (Tables IX to XI). The characteristic of a failure from the one-day group was an extension lag, whereas that from the three-week group was joint stiffness. 


\section{DISCUSSION}

Early assessment-The results were relatively poor, as would be expected when the assessment was made early. However, the purpose of early examination was four-fold. First, a long follow-up

TABLE I

Results of SPlinting for ONe Day

\begin{tabular}{|c|c|c|c|c|c|}
\hline Finger & Excellent & Good & Fair & Poor & $\begin{array}{c}\text { Total } \\
\text { patients }\end{array}$ \\
\hline Index . & 2 & 4 & - & 5 & 11 \\
\hline Middle & 3 & 7 & 3 & 4 & 17 \\
\hline Ring . & 2 & 2 & 1 & 1 & 6 \\
\hline Little . & 1 & - & - & - & 1 \\
\hline Total number & 8 & 13 & 4 & 10 & 35 \\
\hline Total per cent & 6 & & 11 & 29 & 100 \\
\hline
\end{tabular}

TABLE II

Results of SPLINTING fOR TEN DAYS

\begin{tabular}{|c|c|c|c|c|c|}
\hline Finger & Excellent & Good & Fair & Poor & $\begin{array}{c}\text { Total } \\
\text { patients }\end{array}$ \\
\hline Index & 10 & 7 & 3 & 6 & 26 \\
\hline Middle & 20 & 13 & 4 & 2 & 39 \\
\hline Ring . & 2 & 3 & 1 & 1 & 7 \\
\hline Little & 8 & - & - & - & 8 \\
\hline Total number & 40 & 23 & 8 & 9 & 80 \\
\hline Total per cent & 7 & & 10 & 11 & 100 \\
\hline
\end{tabular}

TABLE III

Results of Splinting for Three Weeks

\begin{tabular}{|c|c|c|c|c|c|}
\hline Finger & Excellent & Good & Fair & Poor & $\begin{array}{c}\text { Total } \\
\text { patients }\end{array}$ \\
\hline Index & 3 & 1 & - & 2 & 6 \\
\hline Middle & 6 & 3 & - & 3 & 12 \\
\hline Ring . & - & 2 & - & - & 2 \\
\hline Little & - & 1 & - & 1 & 2 \\
\hline Total number & 9 & 7 & 0 & 6 & 22 \\
\hline Total per cent & \multicolumn{2}{|c|}{73} & - & 27 & 100 \\
\hline
\end{tabular}

was not possible in these patients. They seldom returned for medical examination after payment of compensation, and most soon left the area on completion of their contracts in the mines.

VOL. $47 \mathrm{~B}$, NO. 1 FEBRUAARY 1965 
TABLE IV

Results of the Five Wounds that Became Infected out of the THIRTY-FIVE SPLiNTED for ONE DAY

\begin{tabular}{|c|c|c|c|c|c|}
\hline Finger & Excellent & Good & Fair & Poor & $\begin{array}{c}\text { Total } \\
\text { patients }\end{array}$ \\
\hline Index & - & - & - & 2 & 2 \\
\hline Middle & - & 1 & - & - & 1 \\
\hline Ring & - & 1 & - & - & 1 \\
\hline Little & 1 & - & - & - & 1 \\
\hline Total & 1 & 2 & 0 & 2 & 5 \\
\hline
\end{tabular}

TABLE V

Results of the Fifteen Wounds that BeCame INFECted out of the Eighty SPLinted for Ten Days

\begin{tabular}{|c|c|c|c|c|c|}
\hline Finger & Excellent & Good & Fair & Poor & $\begin{array}{c}\text { Total } \\
\text { patients }\end{array}$ \\
\hline Index & - & - & - & 2 & 2 \\
\hline Middle & 5 & 4 & 1 & - & 10 \\
\hline Ring & - & 1 & - & 1 & 2 \\
\hline Little & 1 & - & - & - & 1 \\
\hline Total & 6 & 5 & 1 & 3 & 15 \\
\hline
\end{tabular}

TABLE VI

Results of the Four Wounds that BeCAME INFECTED OUt OF THE TWFNTY-TWo SPLINTED for THREE WeEKS

\begin{tabular}{|lccccc|}
\hline Finger & Excellent & Good & Fair & Poor & $\begin{array}{c}\text { Total } \\
\text { patients }\end{array}$ \\
\hline Index & - & - & - & 1 & 1 \\
\hline Middle & 1 & - & - & 1 & 2 \\
\hline Ring & - & 1 & - & - & 1 \\
\hline Little & - & - & - & - & 0 \\
\hline Total & 1 & 1 & 0 & 2 & 4 \\
\hline
\end{tabular}

TABLE VII

THE TIME OFF WORK

\begin{tabular}{|l|ccc|}
\hline $\begin{array}{c}\text { Duration } \\
\text { of } \\
\text { splintage }\end{array}$ & \multicolumn{2}{c|}{ Time off work in days } \\
\hline One day & Average & $\begin{array}{c}\text { Least } \\
\text { One }\end{array}$ & Most \\
\hline Ten days & $\frac{12 \cdot 3}{16 \cdot 3}$ & 10 & 28 \\
\hline Three weeks & $27 \cdot 3$ & 21 & 49 \\
\hline
\end{tabular}

* One patient off work for sixty days.
TABLE VIII

Patients Requiring Physiotherapy

\begin{tabular}{|l|c|c|}
\hline $\begin{array}{c}\text { Duration of } \\
\text { splintage }\end{array}$ & $\begin{array}{c}\text { Number of } \\
\text { patients }\end{array}$ & $\begin{array}{c}\text { Percentage } \\
\text { of group }\end{array}$ \\
\hline One day & 9 & 26 \\
\hline Ten days $\cdot$ & 16 & 20 \\
\hline Three weeks & 6 & 27 \\
\hline
\end{tabular}

THE JOURNAL OF BONE AND JOINT SURGERY 
Second, over a course of time a natural improvement had been noticed, of which examples are shown in Table XII, in patients not included in this series. Stewart (1936) reported the natural recovery of tendons after their resection in the legs of cats. This is well known in man and reported by Bunnell (1948) and Flatt (1955). With this natural tendency to improve it is reasonable to suppose that, in the course of time, the three groups could have achieved similar results. It was in order to offset this possible natural levelling that an assessment was made early, and thus to bring out the differences. Other things being equal, such differences could only be due to the varying periods of splintage in the three groups. Third, late complications, if they should occur, would not affect the initial results. Last, because the

TABLE IX

Details of the Poor Results in Those Splinted for One Day

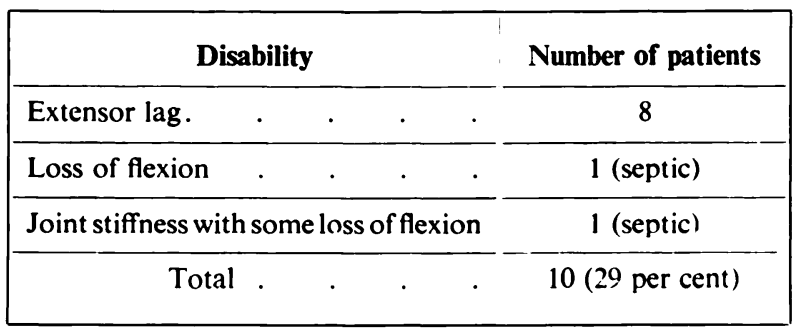

TABLE X

Details of the Poor Results in Those Splinted for Ten Days

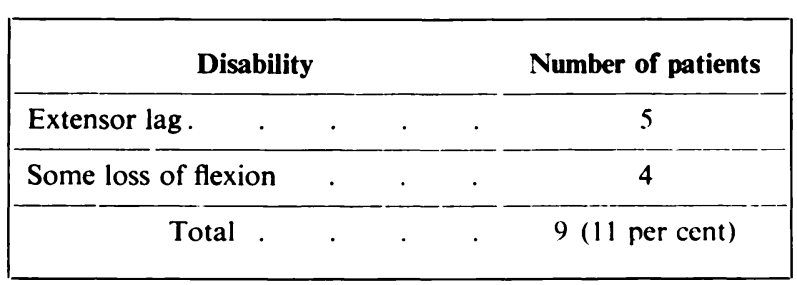

TABLE XI

Detalls of the Poor Results in Those Splinted for Three Weeks

\begin{tabular}{|lllllll}
\hline \multicolumn{3}{|c|}{ Disability } & & & & Number of patients \\
\hline Extensor lag & $\cdot$ & $\cdot$ & $\cdot$ & $\cdot$ & $\cdot$ & $\cdot$ \\
\hline Joint stiffness with loss of extension and flexion & 0 \\
\hline Total & $\cdot$ & $\cdot$ & $\cdot$ & $\cdot$ & $\cdot$ & 6 \\
\hline
\end{tabular}

patients had actually been back at their definitive work for at least a month the state of repair at that stage was considered important. However, assessment was made at a time which was considered to be reasonably comparative for all three groups.

Results following infection-Slight infection recorded did not always lead to a poor result; if it did there was always joint stiffness, but those patients splinted for ten days had the best results. The significance of the poor results-There was a high percentage of poor results in the groups splinted for only one day and for three weeks. In the first group an extension lag was common, but in the last, stiffness and a loss of flexion was most frequent. The poor results from those immobilised for ten days were either an extension lag or loss of flexion, but this group, it must be remembered, had the best results. This suggests that ten days' immobilisation was sufficient to allow repair and to avoid an extension lag but not too long to cause finger stiffness or loss of flexion.

VOL. 47 B, NO. 1, FEBRUARY 1965 
Apart from the period of splintage the conditions did not vary significantly. As an indication of this the percentage of patients splinted for ten days with excellent results in the first part of the series was 78 per cent (twenty-five patients), and the percentage similarly treated in the following six months was 79 per cent (thirty-eight patients).

Although this study deals with the repair of extensor tendons after incised wounds, the period of splintage might also apply in other conditions affecting extensor tendons. If, for instance, there is already a strong tendency for the joints to stiffen in splintage-such as in rheumatoid arthritis or extensive crush injuries-immobilisation for longer than ten days might be hazardous.

TABLE XII

EXAMPLES OF Results IMPROVING With Time.

(All dates are in the same year)

\begin{tabular}{|c|c|c|c|c|c|c|}
\hline \multirow{2}{*}{$\begin{array}{l}\text { Case } \\
\text { number }\end{array}$} & \multirow{2}{*}{ Finger } & \multirow{2}{*}{$\begin{array}{c}\text { Date } \\
\text { injured }\end{array}$} & \multicolumn{2}{|c|}{ First assessment } & \multicolumn{2}{|c|}{ Second assessment } \\
\hline & & & Result & Date & Result & Date \\
\hline 1 & Ring & January 29 & Lost 30 degrees extension & March 2 & Excellent & June 12 \\
\hline 2 & Middle & January 26 & Lost 30 degrees extension & February 23 & Excellent & July 3 \\
\hline 3 & Index & February 2 & Slight loss of flexion & June 12 & Excellent & July 17 \\
\hline 4 & Index & April 21 & Slight loss of flexion & June 12 & Excellent & July 17 \\
\hline 5 & Index & April 4 & $\begin{array}{l}\text { Slight loss of flexion } \\
\text { and extension }\end{array}$ & June 12 & Excellent & July 24 \\
\hline
\end{tabular}

In this investigation the average Bantu worker returned to heavy work 6.3 days after removal of his splint, which had been on for either ten days or three weeks. In the former group this was within seventeen days of the tendon repair and this indicates the ability of the extensor tendon to join firmly in that time.

Rigid fixation of the metacarpo-phalangeal joint may carry a risk of joint stiffness, and this may have marred the results of the three-week group. However, the method employed (Figs. 2 and 3) allowed movement of the distal joints, and with the change of position of the metacarpo-phalangeal joint into slight flexion on the tenth day, probably did not amount to a rigid fixation. To allow joint movement while protecting the tendon is difficult to regulate in practice and some form of splint is usually necessary. Also, despite the fact that the plaster slab held every finger for three weeks, stiffness was not found in the uninjured fingers as might have been the case had there been rigid fixation.

This study of the periods of immobilisation does not apply to flexor tendon repairs where the conditions and the extent of movement required of the tendons are entirely different. Perhaps also flexor tendons have no natural process of repair (Bunnell 1948), although this is denied by others.

Mason and Allen's (1941) original experimental work not only dealt with the strength of the tendon repair, but it also emphasised that, for some time after the join was firm, reaction was likely to occur with movement. It was in order to avoid this, with its consequent adhesions, that they advised a long period of immobilisation. Unfortunately, this had come with general use, but it seems to be unnecessary in extensor tendons where adhesions are not so important. The results in this study of the repair of extensor tendons in man do not justify prolonged immobilisation.

\section{CONCLUSIONS}

Early assessment of the results after primary repair of extensor tendons cut over the metacarpo-phalangeal joints of the fingers showed that more excellent or good results were obtained in those patients splinted for ten days or three weeks than in those splinted for only 
one day, in whom many more poor results occurred; also slight infection was less likely to lead to a poor result in those splinted for ten days. Splinting for only one day tended to give an extension lag, but splinting for three weeks produced considerable joint stiffness. The largest percentage with good or excellent results, and the lowest percentage with poor results, was in those patients splinted for ten days, in whom there was much less tendency for an extension lag or joint stiffness. They also needed less time off work than those splinted for three weeks and fewer needed physiotherapy. Splintage for three weeks produced no better results but caused more joint stiffness and these patients were off work longer and needed more physiotherapy than the others. Reference to Mason and Allen's work emphasises that their advised lengthy period of immobilisation was intended to prevent an inflammatory reaction. This applies more to flexor than to extensor tendon repairs.

\section{SUMMARY}

1. This clinical investigation compares the results with varying periods of immobilisation after the primary repair of extensor tendons over the metacarpo-phalangeal joints of the fingers.

2. One hundred and thirty-seven Bantu mine workers with such injuries were each splinted for either one day, ten days or three weeks, and the results were compared.

3. The results indicate that the optimum period of splintage is ten days.

I wish to thank my fellow medical officers at the Ernest Oppenheimer Hospital for allowing me to supervise their patients, and particularly $\mathrm{Dr} \mathrm{T}$. Leontsinis and Mr E. G. Ahern in the initial preparation of this article. Latterly, I am indebted to Professor Robert Roaf and Mr Roy Pearson for their advice and also to Mrs Meriel Jackson for her help.

\section{REFERENCES}

Bunnell, S. (1948): Surgery of the Hand. Second edition, pp. 382, 383 and 386. Philadelphia, London, Montreal: J. B. Lippincott Company.

Clarkson, P., and Pelly, A. (1962): The General and Plastic Surgery of the Hand, p. 152. Oxford: Blackwell Scientific Publications.

Couch, J. H. (1939): The Principles of Tendon Suture in the Hands. Canadian Medical Association Journal, $41,27$.

Farquharson, E. L. (1950): In Pye’s Surgical Handicraft. Sixteenth edition, p. 428. Bristol: John Wright $\&$ Sons Ltd.

Flatt, A. E. (1955): Minor Hand Injuries. Journal of Bone and Joint Surgery, 37-B, 117.

Flatt, A. E. (1959): The Care of Minor Hand Injuries, p. 73. St Louis: The C. V. Mosby Company.

Handfield-Jones, R. M. (1949): In The Essentials of Modern Surgery. Third edition, p. 1207. Edinburgh: E. \& S. Livingstone Ltd.

Iselin, M. (1955): Chirurgie de la Main. Second edition, p. 224. Paris: Masson et Cie.

Kelly, A. P., Jun. (1959): Primary Tendon Repairs. Journal of Bone and Joint Surgery, 41-A, 581.

КосH, S. L. (1943): Nerve and Tendon Injuries. Bulletin of the American College of Surgeons, $28,125$.

Mason, M. L., and Allen, H. S. (1941): The Rate of Healing of Tendons. Annals of Surgery, 113, 424.

MAYER, L. (1938): Repair of Severed Tendons. American Journal of Surgery, 42, 714.

Miller, H. (1942): Repair of Severed Tendons of the Hand and Wrist. Surgery, Gynecology and Obstetrics, 75, 693.

Nemethi, C. E. (1956): Extensor Tendons in the Industrially Injured Hand. Industrial Medicine and Surgery, $25,113$.

Pulvertaft, R. G. (1956): Tendon Grafts for Flexor Tendon Injuries in the Fingers and Thumb. Journal of Bone and Joint Surgery, 38-B, 175.

RANK, B. K., and WAKefield, A. R. (1953): Surgery of Repair as Applied to Hand Injuries, p. 112. Edinburgh and London: E. \& S. Livingstone Ltd.

Romanis, W. H. C., and Mitchiner, P. H. (1948): The Science and Practice of Surgery. Eighth edition. London: J. \& A. Churchill Ltd.

Stewart, D. (1936): An Experimental Study of the Return of Function after Tendon Section. British Journal of Surgery, 24, 388.

Thatcher, H. H. (1957): Hand Injuries. Early Treatment of Injured Flexor and Extensor Tendons. Northwest Medicine, 56, 827.

VOL. 47 B, NO. 1, FEBRUARY 1965 